\title{
Histone deacetylase inhibition leads to neuroprotection through regulation on glial function
}

\author{
Xuefei $\mathrm{Wu}^{1,2^{*}}$, Shao $\mathrm{Li}^{1}$, Qiong Wu' ${ }^{1}$, Yan Peng ${ }^{1}$, Deqin $\mathrm{Yu}^{1}$, Hecheng Wang ${ }^{2}$, Dehua Chui ${ }^{2}$, Jie Zhao \\ From Molecular Neurodegeneration: Basic biology and disease pathways \\ Cannes, France. 10-12 September 2013
}

\section{Background}

Epigenetic mechanisms such as post-translational histone acetylation are increasingly recognized for their contribution to gene activation and silencing in the brain and contribute to neurodegeneration. Acetylation degree of histones is highly regulated by the enzymes known as histone acetyltransferases (HATs) or histone deacetylases (HDACs). HDAC inhibition affects the expression of only a small subset of genes, leading to transcriptional activation or repression through hyperacetylation of histone or non-histone proteins. HDAC inhibitors are a class of compounds that interfere with the function of HDAC and have been viewed as promising agents to combat neurodegenerative diseases such as Alzheimer's disease (AD) and Parkinson's disease (PD). Multiple mechanisms underlying the effects of HDAC inhibitors on neuroprotection and restoration of memory and motor impairments in AD or PD models have been proposed, however, little is known about the contribution of HDAC inhibition in glial cells. It has been reported that valproic acid (VPA), a drug commonly used for epilepsy and bipolar disorders, upregulates the expression of neurotrophic factors, including glial cell line-derived neurotrophic factor (GDNF) and brain-derived neurotrophic factor (BDNF) in astrocytes, which contributes to VPAmediated neurotrophic effect on dopamine neurons. VPA also induces microglia apoptosis and suppresses the production of proinflammatory factors in microglia. As VPA is a HDAC inhibitor, we hypothesize that HDAC inhibition may contribute to neuroprotection through regulating gene expressions in glial cells.

'Department of Physiology, Dalian, Liaoning Province, China

Full list of author information is available at the end of the article

\section{Materials and methods}

We thus investigated the effects of several HDAC inhibitors including VPA, trichostatin (TSA), sodium phenylbutyrate (4-PBA) and nicotinamide, on neurotrophic and proinflammatory functions of astrocytes and microglia.

\section{Results}

Our results indicate that (1) VPA and TSA increased GDNF and BDNF transcripts in astrocytes that might be attributable, at least in part, to histone hyperacetylation in specific gene promoters as GDNF promoter activity and promoter-associated histone $\mathrm{H} 3$ acetylation level were elevated; (2) both 4-PBA and nicotinamide decreased the cell viability and release of TNF alpha and nitric oxide from cultured microglia stimulated with the inflammagen lipopolysaccharide (LPS). (3) VPA, TSA and 4-PBA protected dopamine neurons in neuron/glia co-cultures challenged with MPTP or LPS; (4) PBA reduced TNF alpha expression in the brain of C57 mice intraperitoneally injected with LPS with no effect on microglia cell count.

\section{Conclusions}

In summary, histone acetylation is involved in regulation of glial functions and may thus contributes to neurodegneration or neuropretection. Further studies on HDAC inhibition in glial cells in AD and PD animal models are warranted to gain a more comprehensive understanding of the mechanisms underlying actions of HDAC inhibitors in the brain.

\section{Acknowledgements \\ This study was supported by the grants from the National Natural Science Foundation of China (30973519) and Research Fund for the Doctoral \\ Program of Higher Education of China (No. 20122105110010).}




\section{Authors' details}

${ }^{1}$ Department of Physiology, Dalian, Liaoning Province, China. ${ }^{2}$ Neuroscience

Research Institute, Peking University, China.

Published: 13 September 2013

doi:10.1186/1750-1326-8-S1-P49

Cite this article as: Wu et al:: Histone deacetylase inhibition leads to neuroprotection through regulation on glial function. Molecular

Neurodegeneration 2013 8(Suppl 1):P49.

Submit your next manuscript to BioMed Central and take full advantage of:

- Convenient online submission

- Thorough peer review

- No space constraints or color figure charges

- Immediate publication on acceptance

- Inclusion in PubMed, CAS, Scopus and Google Scholar

- Research which is freely available for redistribution

Submit your manuscript at www.biomedcentral.com/submit
Ciomed Central 